1939

\title{
Osteochondritis dissecans of the knee joint
}

Rudolph G. Schmidt

University of Nebraska Medical Center

This manuscript is historical in nature and may not reflect current medical research and practice. Search PubMed for current research.

Follow this and additional works at: https://digitalcommons.unmc.edu/mdtheses

Part of the Medical Education Commons

\section{Recommended Citation}

Schmidt, Rudolph G., "Osteochondritis dissecans of the knee joint" (1939). MD Theses. 773.

https://digitalcommons.unmc.edu/mdtheses/773

This Thesis is brought to you for free and open access by the Special Collections at DigitalCommons@UNMC. It has been accepted for inclusion in MD Theses by an authorized administrator of DigitalCommons@UNMC. For more information, please contact digitalcommons@unmc.edu. 
OSTEOCHONDRITIS DISSECANS OF THE KNAR JOINT

Rudolph G. Schmidt

\author{
Senior Thesis Presented \\ to the
}

University of Nebraska College of Medicine

Omaha Nebraska

1939 
PRRPACE

In presenting the subject of osteochondritis Dissicans of the Knee Joint as my senior thesis, I have teled to cover a subject of particular interest to myself, having once been a sufferer with this disease entity. The scope of this paper will be limited to a review of the American Iiterature, the course and treatment of the disease. The technie of operative proceedures has intentionally been omitted.

I wish to axpress my appreclation to Herman $I$. Johnson, M.D., for the loan of his personal case histories which have been presented in this paper. I also wish to take this opportunity to express my appreciation to Wagoner and Coh, from whose article I have quoted at great Iength. 
TA B I O $\mathrm{F}$ CONTENTS

1. Introduction

2. Bt lology

a. Traumatie

b. Non-Traumatic

3. Case Reports

4. Sympt oms

5. Physical Pxamination

6. Pathology

7. Treatment and Prognosi.

8. Comments

9. Summary

10. Bibliography 


\section{OSTBOCHONDRITIS DISSTECANS OF THE KNEE JOINT}

Osteochondritis Dissecans is a non-infectious process involving the articular cartilage and the subchondral bone of certain long extremities, which by sequestration from the articular surface produce loose bodies in the joint. This body is originally. of an osseocartilaginous composition but its structure subsequently undergoes alteration by action of the fluid of the joint. The knee joint is involved in 85\% of the cases according to Conway, in 1937. The mesial half of the articular surface of the internal femoral condyle is the most frequently involved site but the heads of the radius, humerus, lateral head of the femoral condyle, and the ankle may also be sites of the process. Osteochondritis Dissecans occurs most commonly in the young robust youths, most frequently males; probably because of the vigorous sports in which they participate. (Nagoner-1931). The first record of this condition in the literature is given credit by King (1932) to Ambroise Pare, who in 1558 removed a stone from the knee following which there was complete recovery.

Roswell Parks, in 1891, describes six possible etiological causes in his article on "Loose Bodies 
in the Knee". I quote as follows:

1. Hypertrophy and metamorphosis of the synovial fringe. The fringe may hypertrophy and form a small nodule. By some mechanical means the nodule becomes free in the joint.

2. Hypertrophy and metamorphosis of extra synovial tissue around the joint may $g r o w$ and bulge into the joint, and by the same mechanical means become free in the joint.

3. Periosteal outgrowth--Really amounts to a tumor.

4. Organization of effused fibrin and blood. This was f1rst mentioned by John Hunter.

5. Cartilaginous overgrowth.

6. Detachment by injury of some normal tissue.

This condition was christened by Koenig in 1888 , (Phemister 1924). He reported cases with pathological examination and called attention to the frequent absence of history of trauma. His conclusions were that while some of the loose bodies from the articular surfaces are broken of $f$ by trauma the majority are broken off by a disease process of unknown nature which implies that the process is inflammatory but bacterial examination was not made, and his gross and microscopic findings fail to show active inflammatory changes either of the synovial lining or of the loose bodies.

Loose bodies in the joints are found in conditions other than that of Osteochondritis Dissecans. Until this distinct disease entity was named by Koenig, in 
1888, such bodies were grouped under the common heading of "joint mice". The common causes of joint mice are briefly:

1. Osteochondritis Dissecans.

2. Free bodies of traumatic origin which arise in otherwise normal joints. An example is found in fractures of the semilunar cartilages.

3. Free bodies may appear in joints that are the site of arthritis deformans. These bodies arise by the traumatic or necrotic freeing of articular cartilaginous plaques, hypertrophic bony spurs, bony joint papillae, metaplastic cartilage or hypertrophic fibrinous synovial villi. These bodies are usually present in large numbers and vary greatly in size.

4. The poypold bodies present in Charcot's joint.

5. Masses of uric acid salts of various sizes found in gouty joints.

6. Osteolytic sequestrations.

7. Parts of tumors of the capsule in chondromatosis of a joint.

8. Fibrous or lipomatous joint papillae.

9. Parts of hypertrophic synovial vilil following 

a synovitis.

10. Aice bodies commonly described as the result of tubercular imolvenent of structures adjacent to the joint.

11. Following hemorrhage into, or inflammation of a joint; masses of fibrin may result and lay free within the joint.

12. Poreign bodies from external sources.

The 11terature of Osteochondritis Dissecans is divided into two large divisions; those in which trauma is set forth as the chief etiological factor and those in which factors other than trauma are considered as the etiological agent. It is my bellef that the history can best be traced by presenting the various theories of etiology in chronological order. In this paper the theorles of etiology will be presented in two parts, the two schools of thought being presented separately.

Theories of Btiology With a Traumatic Basis

Konro, In 1726, (wolback 1928), advanced the theory that joint mice were of traumatic origin. He was supported by Reimer in 1770, and by Haller in 1776. (Wagoner 1931).

In 1848, iney (Wolback 1928) observed that 
fragments of cartilage and bone, detached as the reault of trauma, continue to grow and become sizeable loose bodies.

Brodhurst, in 1861, and Poncet, in 1881, contended that loose bodies were the result of trauma and arthritis deformans. (Wagoner 1931).

Kragelund, in 1884, assumed a trauma of the bonecartilage area followed by the demarcation and separation of a portion of this area as the result of a chronic inflammatory process. (Wagoner 1931).

In 1887, Wagoner (1931) experimenting on the knees of cadavers corroberated the opinion of Paget by $f$ inding that it was impossible to detach a fragment of articular cartilage simply by a blow; an area could be loosened in this manner, but a prying force was necessary to separate it.

Burghard, (1892), found that an oblique blow upon the internal condyle with the knee flexed may with difficulty produce a complete separation of a piece of the articular cartilage.

Lane, (1893), emphasized the fact that during flexion considerable portions of the articular surfaces are exposed to trauma. Since this area is practically devold of nerve supply be suggests that 
even minor trauma, applied at the right angle might produce these fractures.

sxperimentally on animals, in 1896, Hildebrand (Wagoner 1931) was unable to obtain permanent free bodies by surgical detachment of fragments of cartilage or cartilage and bone.

Preiser, 1898, considered Osteochondritis Dissecans to be the result of static imperfection. (Brackett 1917). Harris, in 1901, makes the statement that almost no one who reports a case who does not reach the conclusion that Koenig was wrong.

Boerner, in 1903, (Wagoner 1931) considered the production of loose bodies upon purely a mechanical basis.

While assisting with an operation, codman (1903) noted that the bodies had the same general configurations as did scars often found on the articular surface. Further studies done on cadavers convinced him that this condition was the result of trauma. He also drew the conclusion that two injuries were necesary to produce a free body, one injury to produce the fracture, and one to free the fragment.

corntl and Coydray, in 1905, (Tagoner 1931) found that bodies of traumatic origin produced through ex- 
periment in animals became united to the articular extremity of the bone or to the synovial membrane of the jolnt, thus upholding the work of Hildebrand in 1896.

Conflicting reports, however, came from Riman in the same year (Wagoner 1931), who following experiments on both dogs and goats stated "there is neither a secondary nor a primary Osteochondritis Dissecans." True free joint bodies arise only upon a traumatic basis.

Ludlofe, in 1908, (wagoner 1931) advanced the theory that loose bodies were the result of injury to the arteria genu media at a point where the artery perforates the capsule, the resulting infarct leading to necrosis of the area of bone supplied by this artery. The necrotic bone gradually separating because of insufficient nourishment. It has, however, been shown that this is not an end artery. There is some contention, however, that the collateral circulation in the articular cartilage is not a functional collateral circulation.

Axhauser, in 1914, (Wagoner 1931) assumed that $\nabla 10 l e n c e$ played a slightly different role. As a result of the impaction from the forces of the blow, injury 
occurred to the vessels. This would lead to necrosis of the bone supplied by the damaged vessels. Instead of the creeping substitution which would take place in quiet necrosis, Axhauser believes, that a zone of absorption is established resulting in a gradual separation and eventual extrusion into the joint.

Friedrich, in 1913, and Bernard, in 1925, (Wagoner 1931) both favored the theory of traumatism.

Fisher, in 1920, stated that detachment could occur by indirect injury through tension upon the posterior Iigament of the knee joint, which is attached immediately adjacent to the articular margin and is powerfully reinforced by the tend ons of the gastrocnemius and semimembranosus. To strengthen his argument for trauma, Fisher chiseled off a small piece of articular cartilage, together with a portion of the underlying bone from the femoral condyle of a rabbit. "The portion was completely detached and pushed up into the suprapatellar recess of the joint", and then closed. Five weeks later the loose body was removed and examined microscopically. His findings did not uphold the findings which would be expected in a quiet necrosis as explained by Paget.

Kappis, in 1920, (Wagoner 1931) pointed out that in 
the knee and elbow which are the common seat of loose bodies, tangential and rotating forces may act on the convex surface of the condyle causing a fissure and partially or completely detaching a portion of the articular end. To explain the traumatic origin in the absence of a history of serious in.jury he assumes that the articular cartilage has little or no nerve supply and the underlying spongy bone is extremely insensitive. This would permit the occurrence of serious injury with little or no serious pain.

Phemister, in 1920, believed Osteochondritis Dissecans in all cases to be a fracture caused by mechanical relationships or slight unnoticeable trauma which results in either complete or partial separation of the loose bodies.

Hellstrom, in 1922, (Wagoner 1931) first expounded the subchondral fracture theory. The fallure of firm healing of the fracture completes the clinical picture. He states that in giving legal opinion, the disease must be regarded as an occupational disease produced by trauma.

xperimentally, in 1923, Freiberg, by means of $x$-ray studies of five cases and the knees of a number of cadavers found that it was quite easy to make the 
tiblal tubercle impinge upon the posterior crucial IIgament when the knee was flexed and the tibia rotated outward. In cases where the tubercle was long, the imp.ingement occurred much sooner and it seemed more easily conceivable that it might take place with enough force to damage a small vessel, but he is more inclined to look upon this condition purely from the traumatic origin.

In 1923, Burckhardt (Wagoner 1931) experimented on cadavers and showed that injury of the median condyle takes place from pressure on the patella. By calculation according to the laws of mechanies it was shown that sufficient force could be derived from contraction of the quadriceps extensor muscle to produce a fracture. Schmidt, in 1924, (Wagoner 1931) demonstrated on the cadaver that at the level of the condyles the cartilage in the joint was more easily injured by a tangential than by a vertical force. By varying the position of the patella when the leg was internally or externally rotated, he found that the patella came in contact with the external condyle when rotated outwardy, and with the internal condyle when the leg is rotated inwardly. He claimed that condylar fragments are broken of $f$ by impacts between the patella and the condyles following 
sudden rotations of the leg in flexion.

Phemister, in 1924, was unable to create loose bodies in the joints of dogs, either experimentally With force, or with the use of radium. He found that bone chipped off and then reinserted in its bed became reattached or was absorbed and disappeared in a couple of months.

Hauptli, also in 1924, (Wagoner 1931) stated that Osteochondritis Dissecans was purely traumatic, complete or incomplete detachment of cartilage, or bone and cartilage in the joint space. He found that if the bits are incompletely broken of $f$, the process of healing in the fragment leads to rudimentary callous formation and now and then to consolidation. The movement and trauma of daily life is sufficlent to prevent this consolidation and cause detachment into the knee joint. He also believes that there is a predisposition to the disease, probably due to special bone conflguration in the joint, hyperthyroidism or hypothyroidism, late rickets, or most of all by an arthritic constitution.

Leb, also in 1924, (Wagoner 1931). concluded that since no chronic inflammatory process could be demonstrated, this theory should be discarded: He believed the disease could be explained completely by joint 
fractures.

Von Dittrich, in 1925, (Wagoner 1931) thought that Osteochondritis Dissecans was the result of mechanical and functional traumatic influence.

Balensweig, in 1925, believed that Osteochondritis was the result of an osteochondral fracture of the external condyle of the femur as a result of cross strain, aided by the pull of the anterior crucial ligament.

Folback and Allison, in 1928, described the condition as the effect of mechanical pressure on a portion of the articular cartilage with underlying. cancellous bone bridging a cyst. In order to have a working theory on this basis, there must be sufficient loss in the condyle of the cancellous bone to weaken the support of the articular cartilage in a position to produce strain upon its covering.

Ri chards (1928) described a case with bilateral involvement in which be found, by means of the $x-r a y$, that the mesial tubercle of the tibial spine was elongated. He therefore suggested a purely local traumatic process.

Krida, in 1930, stated that he had never operated on a case in which be could hold any other etiological factor except trauma. He states, however, that Dr. Milch, 
h1s assoniate, believes Osteochondritis Dissecans to be a group of conditions in which trauma is only one phase.

That Osteochondritis Dissecans was the result of a subchondral fracture, was the belief of Itttlejohn in 1933. In fact he belleved that because of a semilarity of history, signs and symptoms, x-ray appearances and course, all osteochondridities may be explained on that basis. He assumed that the cartilage is insensitive and that the underlying bone, which is devold of periostium has only a very meager nerve supply. By directing a blow on the patella, the force would be transmitted through the articular. cartilage which acts as an elastic sponge, split off from the underlying bone of the condyle; a chip much the same as a blacksmith by pressure with a piece of wood takes flake of $f$ his flint. The elasticity of the cartilage prevents it from splitting with the bone, and thus a subchondral fracture is born. Because of the relative small amount of pain present, the jolnt would soon be in use again. Because of rocking of the fragment in Its bed as the result of weight bearing and movements, non-uni on would most l1kely occur. Hon-uni on implies a fibrocartilaginous covering for the adjacent bone 
surfaces, and this is usually found.

Fairbanks (1933) draws certain conclusions following a thorough study of the literature and his own private cases: The typical lesion of osteochondritis Dissecans is a fracture and nothing else for the following reasons:

1. It most frequently occurs in adolescents and young adults indulging in vigorous pastimes.

2. Typical lesions are seen in radiograms and revealed by operation after definite trauma, which in some cases is quite recent.

3. A lesion at the typical site may involve the cartilage only, the detached fragment consisting of normal articular cartilage. In such cases there is a definite history of trauma.

4. There is an entire abscence of any inflammation, both macroscopically or microscopically, in or about the lesions.

5. The naked eye appearances, when operation is performed early, of fer nothing but a simple recent fracture. When sufficient time has elapsed for changes to occur, they are only those which we should expect as the result of an effort on 
the part of tissues to repair the damage. Precisely similar changes are oceasionaliy found on the more exposed parts of the femoral articular surface, where the tramatic origin of the lesion is never disputed.

6. When the detached fragment is aspended by a vascular pedicle, the bone in it is not dead and is not a sequestrum, so why should it be exfoliated.

7. To explain the occurrence of the lesion in both knees or the knees of more than one member of a family, it is easier to accept the presence of anatomical peculiarities which favor exceptional local trauma than the suggestion of embolism, damage to blood ressels, or indeed, any other theory.

He concludes that violent rotation inwards of the tibia, driving the tibial spine against the inner condyle is responsible for the lesion in most cases.

Three distinct incidents of trauma with the production of three bodies was reported by Montel th in 1934 . He found at operation that three bodies were present, and was of the opinion that one was produced with each trauma. 
Conway, Iikewise, in 1934 , states that the most logical explanation seems to be that which allows for a preliminary trauma to a non-sensitive articular surface with subsequent injury to a functional end artery. Following the ressel damage and thrombosis, a locallzed area of necrosis results with sequestration from the articular surface.

Brallsford (1935) was of the opinion that the loose body is the result of sequestration of a small fragment of subchondral bone. This separation is probably due to trauma and subsequent local rascular disturbances.

Leslons of the carpal scapold and the palmer surface of the semilunar hare been described by Funsten and Kinser (1936). They uphold that trauma is the primary cause followed by a localized area of aseptic necrosis stimulating an infarct.

Outland, in 1936, reported a ease in which there was a defect found at operation in the articular cartilages of both condyles following one specific blow.

By means of x-ray, Miller, in 1936, followed a case of Osteochondritis Dissecans of the elbow through the development of the loose body. He is of the opinion that Axhauser's theory can most readily be applied to this condition. 
Galloway and Macey, in 1937, reported a case of bilateral involvement with bilateral dislocation of the patellae. The first history of trauma goes back to the age of six years on the right knee, and fifteen years on the left knee. This leads to the belief that this condition is one of trauma superimposed upon some predisposing anatomical inadequacy, probably rickets.

\section{Theorles of Et1ology With a Non-Traumatic Basis}

Perhaps one of the first theories not supporting the theory of trauma was sonsored by the father of surgery, John Hunter. He believed that the formation of cartilaginous bodies in joints was due to extrarasated blood which assumed the nature of the parts into which it was effused (1793).

Rainey and Solly, in 1848, concluded that the glands of the synovial membrane, instead of secreting synovial lluid, under some unknown influence produced cartilage instead, which later became converted into imperfectly formed bone.

Rokitansky, in 1851, stated that "bodies composed of bone and cartilage might arise from the articular serosa, representing an excessive development and ossification of isolated nodules of cartilagen. (Wolback 
and Allion 1928).

Paget, in 1870, made the statement that "these loose bodies are sequestra, exfollated after necrosio of Injured portions of cartilage, exfollated without acute inflammation.

Kock, in 1879, (Wagoner 1931) performing experiments on embolic necrosis of the bone proved to his own satisfaction that loose bodies were the result of the obstruction of the entire capillary area of mutrition.

Konig, in 1887, described Osteochondritis Dissecans as a separate entity. He concluded that it was a blastIng of a piece of the surface of the joint, which resulted In the severance of a piece of the joint surface without otherwise damaging the joint. He did not deny that trauma did have some part, however, he thought that it served to merely accentuate the damage already present. Konig, howerer, was convinced that the true etiology was obscure.

Roswell Parks, in 1891, described the following as possibilities other than trauma:

1. Hypertrophy and metamorphosis of the synovial fringe. The fringe may hypertrophy and form a amall nodule. By some mechantcal means the nodule become free in the joint. 
2. Hypertrophy and metamorphosis of the extrasynovial tissue. The tissue around the joint grows and bulges into the joint and by the same mechanical means becomes free in the joint.

3. Periosteal outgrowth or in reality a tumor growth.

4. Organization of effused fibrin and blood as assumed by John Hunter.

5. Cartilaginous rergrowth.

Prelser, in 1898, presented the static imperfection theory. He states that improper weight bearing from flat feet and other causes may produce this condition. In the hip, the superior portion of the acetabulum or the superior weight bearing portion of the head of the femur may be affected. (Wyckoff 1938).

In 1903, codman stated that the premelent theory was that loose bodies of the joints were concretions comparable with the formation of biliary and cystic calculi. The supposed nucleus was a clot of fibrin, a piece of cartilage or a bit of torn fringe. Codman, however, belleved trauma to be the true etiology.

Henderson, in 1916, suggested some metabolic condition. He based his opinion on the fact that people are often seen with brittle finger nails, brittle hair, 
brittle bones. He, therefore, thought that it was conceivable to have a brittleness of the articulating surfaces. This combined with the great strain thrown on the internal crucial ligament when the knee is extended, and the constant tugging of this 11 gament might have some effect upon the cartilage.

Axhausen, who at first was a strong advocate of the damage to blood ressels theory, suggested in 1924, that this might be due to embolism. He attributes the lesions to embolic infarction. He suggested attenuated tubercle bacillus, or some bacteria of greatly reduced virulence be deposited, which would lead to closure of an epiphyseal end artery. Since the bacteria are of low virulence they are immediately conquered and the necrosis remains aseptic. Paitre and de Bouguet, also supporting this theory, suggested a "special fragility" of the epiphysis. (Pairbanks 1933).

Bernatein (1925) reported three cases in one family in which the condition occurred bilaterally. Upon tbis he bases the opinion that there must be some familial predisposition to the disease upon which trauma is superi mposed.

Re1ger, in 1920, suggested fat embolism and reported that he found evidence to support it. Howerer, no one 
has ever been able to reduplicate his findings. (Fairbanks 1933 ).

Knaggs in his conception of "the quiet necrosis of Paget" beliered that the initial lesion was one of 10 w grade periostitis due probably to staphlococcus, because of Its low virulenee the infection doep not spread deep in the bone, but is speedily limited. Granulation tissue developing in the deeper structures causes a compressing of the blood ressels with subsequent necrosis. (Fairbanks 1933 ).

Archer and Peterson (1930) are of the opinion that Osteochonditis Dissecans is but one phase of the deforming, non-infectious disease of adolescence, examples of which are Legge-Perthes disease, Kohlor's disease, and sliding epiphysis.

Vagoner and Cohn, in 1931, reported five cases of Osteochondritis Dissecans in members of one family. On this basis they conelude that heredity is a factor in the etiology.

Chormley of the rayo Clinie, In 1932, supported the theory of wolback and Allison, in which cystic degeneration was advanced. He, however, also thinks that there way be ome relationahip between these conditions and the disturbances of epiphyseal growth. 
Metabolic upset was advanced by sterenson and Henderson in 1937. They reported a case in which they were able to demonstrate decalcifieation of other bones as well as the affected bone. Blood studies showed a normal calcium, but urine studies showed a decreased calcium output. This together with the experimental work of Mirvish and Boman upon the effect of gonad extracts on the blood ealcium, lead to the theory that Osteochondritis Dissecans was in reality a temporary hypergonadism. The gonad activity causing a constant lowering of the blood calcium with consequent withdrawal of lime from the bone to maintain the blood level. The normal food calcium supply is either deficient in the circumstances or is insufficiently absorbed and utilized. The result of this process is decalcification. Recurrent trauma is believed to be responsible for the dislodgement of the bodies.

That Osteochondritis Dissecans definitely emulates Iegge-Perthes disease was concluded by Balenoweig, in 1938. He reported a case involing the entire articulating surface of the distal end of the femwr. He tates that "Osteochondritis Dissecans may be looked upon as resembling in great part osteochondritis of the first decade of life, in which, as a reault of faulty nutri- 
tion and permanent damage to the underlying vascular structure, a loose segment of bone is thrown off to produce a resemblance to the subchondral fracture. In other words 0steochondritis Dissecans may be a late stage of certain forms of Osteochondritis Juvenalis.

\section{Case Reports}

Case 1. S. S. A 51 year old female. Six years ago following a twisting fall on the right knee, the knee was twisted medially and bent medially. Pain on the medial and anterior side of the knee. The knee had locked on several occasions. An elastic knee bandage was constantly worn. Walking caused pain in anterior medial aspect of knee. Physical examination showed no swelling or increased fluid. The knee was painful to motion and tender over the medial semilunar cartilage. On flexion there was definite grating. Patient was not operated.

Case 2. D. H. A 34 year old male. Had cartilages removed in 1932. Was well until 3,1937 , at that time following exposure to cold he woke in the. morning with pain, stiffness and swelling in the 
knee. Improved when not on feet. Any further ttempts to walk brought increased pain and swelling. X-ray, AP and lateral showed irregular fragments of bone separating from the medial condyle of the femur measuring about 15 millimeters in diameter and 3 to 5 millimeters in thickness. Arthrotomy was done, followed by recovery.

Case 3. A. J. S. A 58 year old male. Klcked on outer aspect of knee. Patient fell to the ground with the left leg bent under the right. The patella dislocated medially. Patient was treated by immobilization for five weeks, following which, attempts at walking produced severe pain. X-ray showed an area of decreased density in the intercondylar space. Operation-Arthrotomy, medial patellar incision was made. The patella being retracted laterally. A soft whitish area of cartilage on the artieular cartilage was seen. Cartilage was removed down to the normal bone. Checkup showed an approximate disability of $25 \%$.

Case 4. A. F. A 17 year old male. The right knee locked suddenly three days previous. Locking 
persisted. History of painful creaking of knee for ome time although never disabled before this time. Operation showed an almond sized calcareous body attached by a pedicle which was remored from the intercondylar space. Internal cartilage also found relaxed, and was excised. Good recovery.

Gaie 5. C. K. An 11 year old male. Complains of pain on medial aspect of knee when walking and running. Patient had had flat feet ince birth which had improved with treatment. Physical examination howed severly pronated feet, otherwise negative. X-rayed on suspicion. AP view showed Osteochondritis Dissecans very clearly. condition explained, and warned to be careful. Cheekup to follow later.

Case 6. L. D. While playing basket ball two months ago pati nt receired a twisting injury to the right knee. Was forced to discontinue play. Later patient noticed a slip of the knee with each step, Sense of bone rubbing together was also complained of. Iocking had occurred only once. The knee was twisted and the knee unlocked. Pain had continued but was not as 
severe as previously. Occasional swelling had occurred. Patient had been unable to work since the injury. Physical examination showed slight effusion. Upon flexion of the knee, there was definite sensation of bone slipping. X-ray--typical of osteochondritis Dissecans. Three small calcarious bodies were visualized. Operation Arthrotomy of the area found it to be attached to the articular surface of the femur by a pediele. Bodies removed. Complete recovery.

Case 7. A. D. M. A 23 year old male. Patient complained of losking of the left knee on several occastons the past three years. Gives a history of sereral minor injuries. Physical examination showed marked weakness. There was a defect in the central portion of the quadriceps muscle about six inches above the knee. There was demonstrable weakness upon extension. Operation-The internal condylar margin of the articular cartilage of the femur showed irregular proliferation with panus formation. Four bodies were removed. Recovery was satisfactory.

Case 8. B. A. A 22 year old male. About three years 
ago patient developed pain in the right knee. The knee had never locked. There was no history of trauma. The knee gave way suddenly when the pain struck. This usually occurred in partial flexion. The knee was bothergome in changeable weather. The physical examination was negat1ve. X-ray showed posstble early Osteochon- it: dritis Dissecans. Patient was again $x$-rayed six months later at which time the lesion was very clearly visualized. On operation there were no loose bodies. However, there was an area seen about the size of a quarter in which the eartilage had a different color. The osteochondritio area was incised and lifted out. Recovery was sat1sfactory. About two years later this same patient came In complaining of pain and a grinding sensation in the left knee. Again no history of trauma was obtained. $X$-rays at that time were negative. At the same time the patient complained of pain and popping of the right shoulder when the arm was raised orer the patients head. $X$-ray and phyaical examination were both negative. Patient had not returned for a checkup. 
Case 9. F. G. A 20 year old male. Patient complained of pain in the right knee upon exertion. There was only history of minor trauma. Patient stated that the knee never locked, but that it occasionally seemed to slip following which there was usually some effusion. The knee was more painful after a days work. Physical examination revealed only moderate tenderness over the medial condyle. X-ray revealed a typical area of Osteochondritis Dissecans. Operation--the area of Osteochondritis Dissecans was enucliated following which there was complete recovery.

Case 10 K. B. A 21 year old made. Patient states that he suffered a twisting injury to the knee. The knee had not locked but was painful to full extention. Physical examination showed that the patient walked with a limp. Complete extension was painful. There was tenderness over the medial condyle. X-ray showed typical area of Osteochondritis Dissecans. Operation with removal of the bodies was followed by complete recovery.

Case 11. I. A. Patient a 33 year old female. Patient 
stated that she suffered a twisting injury to the right knee about 13 years ago. Since that time she had no definite eonstant symptoms until about 18 months ago when she developed a sensation of giving way and weakness. She dereloped a limp about one year ago and for the last three months she had to go about on crutehes. Physical examination was essentially negative. $X$-ray showed an almond shaped mass in the intercondylar space. Operation--removal of a pedunclated mass of cartilage. An area was seen on the medial condyle which had become filled with granulation tissue. Recovery was satisfactory.

Case 12. R. S. Patient a 24 year old male complained of vague pain on the medial side of the knee with sensations of slipping. Hard to take steps and to walk far. History of trauma on four occasions. Has been operated for deranged cartilage. Knee had never locked. Then knee gave way it seemed to sip medially. There was always effusion following this sensation of giving way. X-ray showed a lesion typical of Osteochondritis Dissecans with one fragment 
in the posterior joint cavity and one in the anterior pouch. Operation Arthrotomy -- four loose bodies removed. Typical Osteocbondrit1s Dissecans bed on the medial condyle of the femur. Recovery was satisfactory.

\section{Sympt oms}

Symptoms of Osteochondritis Dissecans are by no means constant. The typical symptom of a loose body in the joint is that of locking. There is a momentary sudden pain, lasting only a few minutes, the joint remaining fixed in one position until unlocked. This is usually followed by a transient effusion into the joint with moderate synovitis.

This, however, is not a typical chain of events in our small series of cases just presented. The most common symptom is pain. This pain is most often classified as a dull ache usually located over the medial condyle. This pain is more noticeable after walking stairs, running or walking. This pain was present in nearly $100 \%$ of the cases.

Typical locking occurred in only three cases or in $25 \%$ of our series. However, a rather typical slipping is complained of in about $40 \%$ of the cases. This slip- 
ping is described as a sensation of giving way which causes intense momentary pain. There is no characteristic locking, or at least the locking does not persist. This is usually followed by effusion into the joint with tenderness and stiffness.

In two cases pain on walking or weight bearing was so intense that the patient had to go about on crutches. One of these cases was, no doubt, a fracture of the chondrium. The pain began immediately following a traumatic injury and was not relieved by rest and immobilization. The other case was one in which there was a history of trauma thirteen years previously. Until eighteen months ago there were no symptoms. At that time she developed a limp which has progressively become worse, so that the last three months she has had to go about on crutches.

King, in 1932, divided the cases of osteochondritis Dissecans into three general groups as far as symptoms. are concerned:

Group I. This group of symptoms included the extremely painful swollen tender joints, which locked in 15 or 20 to 45 degrees flexion. These symptoms usually began suddenly, a few days previous, subsequent 
to a twist or some other minor injury.

Tere Is usually no previous bistory of disability.

Group II. In this group be included the asymptomatie or slumbering cases of Osteochondritis Dissecans. These cases are usually discovered quite by accident, by means of the x-ray.

Group III. Here he elasses those ehronteally troubled with the joint for 2 or 3 years. Complaint is usually of soreness or definite pain on weight bearing, associated with swelling. "Giving way" and stiffness were also common symptoms.

\section{Physical Signs}

Physical signs are not reliable. If the patient is seen during the acute state or rather immediately following injury there may be painful effusion into the joint. Usually there is pain orer the medial condyle to pressure. crepitus or grating can occasionally be felt on movement - of the joint. Rarely can the joint mouse be palpated. Those eases in which locking occurs it is ometimes possible to palpate the body which will disappear when the 
locking is relieved.

$$
\text { X-Ray }
$$

X-ray lindings in Osteochondritis Dlssecans is usually characteristic. Positive diagnosis can usually be made, however, cases in which the bodies are composed of eartilage it is oecasionally difficult to visualize the individual bodies.

The importance of $x$-ray studies was emphasized by Ridion (1913), Lamson (1921), Richards (1928) and Milier. in 1936.

The knee joint may best be visualized in the AP view. It may also be visualized in the lateral view and if 0 , the additional information provided is of such importance as to make a study in both positions essential.

The defect is seen as a sharply defined shallow depression, irregularly circular in outline and containing in its center a button of bone, the density of which may vary from that of a fully separated sequestrum to one differing so slightly from the normal bone about it as to entirely escape notice. The defect is usually seen upon the outer side of the inner condyle of the femur, immediately opposite the mesial tubercle of the tibial spine. (Ri chard 1928).

Various degrees of derelopment may be observed from 
these cases in which the process is fully established to those which are examined during the early stage of the disease. Miller, in 1936, followed a case of Osteochondritis Dissecans of the elbow through the development of the loose body. From his observations, he concludes, Axhausen's theory can most readily be applied to the condition.

In the fully developed stage the button of bone has the density of a sequestration lying in a sharply defined niche or recess just large enough to contain it. At this stage the loose body is of ten actually what it appears to be, namely a completely separated sequestrum, requiring merely a force under the proper conditions to dislodge it into the joint. In the earlier stages, the button of bone is still attached to the condyle, either by a broad base or by a pediele and its density will be more or less determined by the degree of this attachment. If the degree of separation is slight, it may be that the variation in density between the button and the normal bone of the condyle is so slight as to be easily overlooked. In such a case the only ind cation of its preaence may be an indistinct line of demarcation forming an I rregularly circular outline upon the articular surface of the condyle in this particular location. If 
this line can be established beyond question, it may be considered of diagnostic importance.

\section{Pathology}

Macroscopically, Conway (1937) described, three definite tages in the development of loose bodies as he found it at operation.

The first stage, very early, shows a fairly well demarcated prominence of the articular eartilage covering the area, of a different color than the rest of the cartilaginous surface. When this area was incised, it was rather easy to separate and a beginning excavation of the cancellous subchondral portion of the articular end of the bone was observed.

The second stage showed that the fragment had become distinctly separated and wa lying within the excavated area of the articular surface. Occasionally the fragment was still attached by means of a pedicle. The fragment was easily remoreable. At this stage the fragment showed a distinct color change, having an ivory east in contrast to the normal. In addition the cartilage was not firmly attached to the underlying bone and could be easily removed for a varying distance from the sequestrated focus. 
The ease with which the process could be lifted of gives it the actual appearance of having been dissected of $f$.

The third stage was merely a completion of the first two stages, and was characterized by the complete sequestration of the fragment from its place on the articular surface into the joint cavity.

The character of the synovial membrane lining the joint depends upon the amount of irritation that it has been subjected to from the loose bodies, and also the amount of hemarthrosis present, and the length of time this irritation is present. Changes in the synovial membrane represent all the stages between simple edema of the synovial papillae to a pronounced hypertrophy of the individual, and multiple single papillae which have been in direct contact with the loose body. The extent of this traumatic hypertrophic synovitis is in direct proportion with the amount of irritation and the length of time it is present. There is a striking subsistence of symptoms within a very short time following an arthrotomy.

The pathology seems to be quite constant in osteochondritis Dissecans. Microscopically there is no indication that this. is an inflamatory process. 
It is interesting to note just what is the fate of these loose bodies in the knee. Bly, in 1915, reported a case in which there was a bistory of only one injury. At operation he found the body to be thicker than the place of origin, indicating that growth had taken place.

Fisher, in 1920, chiseled a small piece of articular cartilage together with a small portion of underlying bone from the femoral condyle of a rabbit. The portion was completely detached and pushed up into the suprapatellar recess of the joint. Five weeks later the loose body was removed. Microscopically the findings were almost identical with those found in osteochondritis Dissecans.

Rombold found no evidence of degeneration of the hyaline cartilage. The bone trabeculae were of normal form but no stained cells were seen. The intratrabecular tissue was without blood vessels. Osteoblasts were seen lining several of the trabeculae. In some places the intratrabecular tissue was replaced by fibrocartilage. The fibrocartilage was connected with, and seemed to originate from the hyaline cartilage covering the articular surface of the specimen.

Littlejohn, in 1933, found that the fibrocartilage may be irregularly calcified. Apparently after separa- 
tion of the articular bone from its blood suply, it will die except for a small portion which may obtain sufficient nutrition from the synovial fluid to survive. The growth of the loose body in the carity of the joint, however, is due to proliferation of the fibrocartilage which derives its nutrition from the synovial fluid, and which may undergo several forms of growth. The bed from which the body originates fills and sometimes overfills with fibrocartilage.

In section, the bone will be found to be for the most part dead, although not uncommonly a small portion may be found to be alive. The bed is Iined by fibrocartilage, the growth in thickness of which appears in some cases to have determined the freeing of the body into the joint cavity. In no case was there any evidence of recent fracture or any inflammatory process.

In few cases fine fibrils of connective tissue may connect the body with its bed and in these a larger proportion of the bone cells may survive, deriving some blood supply through these connections. More frequently there may be a vascular hinge formed from the synovial sheath of the posterior crucial ligament, and by its blood supply the bone fragment may survive or even grow. 
In cases detected early and opened before the body is extruded into the joint there is no apparent pathology. On closer inspection a slight difference of color is noticed over the area. The cartilage seems also to have a slight increased sponginess. Incision of the cartilage will disclose the bony fragment lying in its bed.

Wckoff (1937) likewise finds that the findings are quite uniform. The cartilage cells usually show signs of proliferation and the external bone cells are living while those in the center usually show signs of degeneration.

Treatment

The treatment of Osteochondritis Dissecans is Arthrotomy with the removal of the joint bodies. In cases where the fragment lies in the excavation and is not completely detached the piece should be remored. Some men advocate the curetting of the crater, but it is likely that the cavity will eventually fill in with fibrocartilage as is found in cases in which the body has been free in the joint for considerable lenths of time. In some cases it is usually advisable to remove the undermined portion. 
The optimum time for operation is before the fragment has been completely set free in the joint. since the joint changes, namely the synovitis, varies with relation to the amount of irritation and the length of time over which it has been applied, it can be seen that if the fragment is removed before it becomes free in the joint the irritation would naturally be lessened with consequent reduced function.

The technic of arthrotomy will not be discussed in this paper. However, it is worthy of mention that due to Improved asepsis and technic the mortality from this operation has been reduced to a negligible figure. This is interesting in the light of statistics of fered by Larry, in 1860. of 170 operations performed 127 operations were successful, 33 died, and 20 were failures. Mine years later, Benndorff collected 169 cases, 109 of which were successful, 46 died and 14 were failures. Muller, in 1886, gathered 190 cases, $96 \%$ of which were successful and 4\% died. Woodward up to 1889 found 104 cases with 6 bad results, 2 amputations and one death. Benj. Bell, in 1787, while speaking of those bodies in the knee that are not freely moveable, said, "In this case I would advise amputation of the limb". This remedy is no doubt severe, but it is less painful and less 
hazardous than excision of any of these concretions that have been attached to the capsular ligament.

The period of convalescence of these cases is usually entirely uneventful. Motion is usually started about the 12th or 14 th day. Weight bearing is usually safe after about 3 or 4 weeks, and at the end of 8 to 10 weeks the patient has usually ended his period of disability.

It has been found that physiotherapy and massage do much to relieve the residual synovitis and thereby the period of disability is markedly reduced.

In those cases in which it is not adviseable to operate or if for some reason operation is refused, much. can be done to relieve the symptoms by continuous physiotherapy and massage.

The Immediate prognosis is very good. However, it must not be forgotten that in later life the possibility of "rheumatic" aches and pains are greatly increased. The possibility of a recurrence is small after the patient has past the adolescent age. In the series of cases presented only one case was out of the adolescent age. In that case there was no doubt that the injury was that of a fracture of the articular surface purely on a traumatic basis. Once the patient is safely through this period, there is no danger of recurrence except 
from some traumatic accident severe enough to cause a fracture as was mentioned above. 


\begin{tabular}{|c|c|c|c|c|c|c|c|c|c|}
\hline Pationt & $80 x$ & $\Delta 8$ & $\begin{array}{l}\text { S1te of } \\
\text { Invelvement }\end{array}$ & $\begin{array}{l}\text { Iumbes of } \\
\text { Fragentents }\end{array}$ & $\begin{array}{l}\text { History of } \\
\text { Trauma }\end{array}$ & $\begin{array}{l}\text { Imediate } \\
\text { Disability }\end{array}$ & $\begin{array}{l}\text { Hiotory of } \\
\text { Locking }\end{array}$ & xray & $\begin{array}{l}\text { ssoociated } \\
\text { Conditions }\end{array}$ \\
\hline 8.8 & $F$ & 51 & & & YeE & Yes & Yes & Pos. & Megative \\
\hline D.H. & $\mathbf{M}$ & 34 & $\begin{array}{l}\text { Yodilal } \\
\text { Condylo }\end{array}$ & 1 & no & Yos & No & Pos. & Nogative \\
\hline A.J.S. & $\mathbf{x}$ & 68 & $\begin{array}{l}\text { Modial } \\
\text { Condyle }\end{array}$ & 1 & Yes & Yos & No & Pos. & Negative \\
\hline P.F. & $\mathbf{M}$ & 17 & $\begin{array}{l}\text { Intereondylar } \\
\text { space }\end{array}$ & 1 & No & Yos & Yos - & Pos. & Nogative \\
\hline C.X. & $\mathbf{u}$ & 11 & & & No & No & No & Pos. & $\begin{array}{l}\text { Congenital } \\
\text { Flat Foot }\end{array}$ \\
\hline L.D. & $\mathbf{u}$ & 20 & $\begin{array}{l}\text { Ledial } \\
\text { Condylo }\end{array}$ & 3 & Yo8 & Yos & Yes & Pos. & Negative \\
\hline A.D.M. & $y$ & 23 & $\begin{array}{l}\text { Yodial } \\
\text { Condyle }\end{array}$ & 4 & Yes & No & Yos & Pos. & Negetive \\
\hline B.A. & $\mathbf{y}$ & 22 & $\begin{array}{l}\text { Intercond ylar } \\
\text { Space }\end{array}$ & 1 & No & Ho & No & Pos. & $\begin{array}{l}\text { Poentblo Left } \\
\text { loee and shoulder } \\
\text { involvenent }\end{array}$ \\
\hline F.G. & $\mathbf{y}$ & 20 & $\begin{array}{l}\text { Intereonylar } \\
\text { Spece }\end{array}$ & 1 & Yes & No & No & Pos. & Negative \\
\hline $\mathbf{K} . \mathbf{B}$. & $\mathbf{x}$ & 21 & $\begin{array}{l}\text { Interoondylar } \\
\text { Space }\end{array}$ & 2 & Yos & Yos & No & Pos. & Negative \\
\hline L.A. & $\mathbf{F}$ & 38 & Modial Condyl & 1. 1 & Yee & No & No & Pos. & Negative \\
\hline R.8. & $\mathbf{u}$ & 24 & Modial Condyl & 104 & Yos & No & No & Po8. & Negative \\
\hline
\end{tabular}


Following a review of the literature and the study of individual cases let us pass to a discussion of possible theories of etiology. In the series of cases presented trauma of some degree was found to be present in $75 \%$ of the cases. With such a percentage, trauma can not be overlooked as at least a part of the picture. Trauma with injury to blood vessels with the formation of an infarct has been presented as a possible theory. It has been shown that anatomically the arteries to the articular surfaces are not end arteries. It has, however, not been shown that the anatomical collateral eirculation present is a functional collateral circulation. The shape of the bodies is in general against that of an infarct. Comparison here must be drawn to the infarct found in tuberculosis in which there is a definite characteristic wedge shaped cavity which is not present in this condition. For the same reason emboli of elther bacterial or latty origin must be more or less d 1 sregarded.

Pathological studies fail to disclose any evidence of an inflammatory process. This would cast into disregard inflammatory processes either as the result of bacterla or following trauma. A bacterial infectious process would also be unlikely to occur in cases such as those 
which are normally affected by this disease, namely the young, robust adolescent youth. It is unlikely that the cystic degeneration found by Wolback and Allis on is a constant phase. It has never been possible to demonstrate this, and no other similar report has appeared in the I1 terature.

This brings us then to the question of a subchondral fracture with nonunion. It must be admitted that the pathological findings in this condition are strikingly. constant. The detached surface is always covered with fibrocartilage. This finding is consistent with nonunion. It is conceivable that trauma could produce such an injury. There are no associated joint changes to indicate any other process. It has been pointed out that articular surface and subchondral bone is relatively insensitive, and it is possible that severe trauma or injury would not cause ymptoms in any proportion to the damage done. How is the fragment set loose in the joint? Ifttlejohn has gone to great length to show that due to the relative insensitivity of the area, the joint would no doubt be used immediately, provided that in the in itlal damage the cartilage was left unbroken over the site of the subchondral fracture. In this case there would be no effusion of blood or roughened surfaces to 
cause irritation for the setting up of a synovitis. Continued trauma of every day life such as walking would cause rocking of the fragment in its bed. This would be sufficient to cause nonunion. Fibrocartilage fills in the bed and as it gradually grows thicker it pushes the fragment out where only a minor injury or jolt would be necessary to pry it out of its cavity. This has been upheld by pathological studies and Conway describes three definite stages in the derelopment of a loose body as be has found it in his series of cases.

The question might well be brought up as to how this trauma must be applied to produce such a fracture. There have been many possible arenues of force suggested. Since this lesion is most commonly found in the knee, the knee will be used as the example. Force applied on the patella through the range of motion of the knee would in itself cover considerable articular surface. It has also been shown that when the knee is flexed there is a portion of the articular surface which is left unprotected. Then to, there is the damage which might be done by the tibial spine in violent twisting. The site of this lesion in Osteochondritis Dissecans, however, is quite uniformly characteristic. In Chareot's joint of the knee, chips are not infrequently broken of as a result of excessive 
trauma consequent to ataxia and to the loss of the protective sense of deep pain. In this condition, howerer, they never originate from the lateral surface of the mesial condyle or from the inferior surface of the patella, but nearly alway from the margins of the tuberosities of the tibia. This is quite contrary to the expected findings.

Given that trauma may cause a subchondral fracture, does it not seem peeuliar that this should be an entity with such a characteristic age grouping? True, the young robust adolescent youth does participate in strenuous games, but, are there not laborine conditions which are engaged in everyday during which minor trauma is a routine occurrence, but in which this condition does not derelop? I am inclined to beliere that we are dealing with two diatinctly different conditions. In one we have a subchondral fracture as the result of one severe trauma; which may occur at any age; while in the other we have a subchondral fracture superimposed upon some condition which would predispose the indiridual of adolescent age to this entity. In the series of cases reported 10 eases fell within the usual age group of 17 to 24; one case fell in the froup of subchondral fracture as the result of severe trauma, while the other fell 
into a group which Preiser would call tatic imperfection, that is with an associated condition such as congenital flat feet.

Case 8 presents an interesting problem, with no history of trauma, an Osteochondritis dissecans of the right knee developed. This was reliered by artbrotomy. Two years later he again returns complaining of similar pain in the left knee. X-rays, howerer, were negative, and the patient was not operated. At the date of this writing the patient has not returned for a checkup. Does th1s patient fit into the metabolic upset deseribed by Sterenson and Henderson which they attributed to a temporary hypergonadism. It would have been interesting to have had calei um determinations on both the urine and blood. Would the urinary excretion of caleium have been below normal? Would his bone have shown the general decalcification described by Stevenson and Henderson.

Case 5, 11kewtes, is an interesting problem. At the age of eleven, a male boy with severely pronated feet develops a lesion typical of Osteochondritis Dissecans. Was the Osteochondritis Dfsecans due to alteration of the welght bearing lines or was it a case of trauma pure and simple, or was it trauma superimposed upon some growth disturbance? 
In the series of cases presented there were no cases in which more than one member in a family were afflicted. It is conceivable that ome variation in either the blood supply to the subchondral area or in the anatomical structure of the articular surface would predispose members of a family to the same disease entity.

of particular interest to myself, 1 of course, my own case, which is found in case 12. In my case there is defint te history of trauma on four different oceasions. The flret trauma was a blow to the lateral side of the knee while the knee was fully extended. Following the injury there was immediate pain which persisted for a short time followed by some transient tenderness and stiffness. This was seemingly without residual consequences. About one year later the knee suddenly "gave way" while descending a flight of steps. The knee was not locked, but there was great pain present when walking. About one month later a twiating injury was receired. After this injury it was necessary to keep the knee wrapped at all times because of a constant feeling of slipping in the joint, associated with pain. Diagnosis of Deranged semilunar Cartilage was made and operation performed. At operation a mall split was found in the medial cartilage. This was removed and the joint closed. 
Recovery from the operation was without incident. How ever, following this operation there was still a sensation of occasional slipping. About 3 years later still another occasion of trauma following which disability was increased. It was following this injury that the diagnosis of Osteochondritis Dissecans was made and operation performed with relief of symptoms. Then in this chain of events did the Osteochondritis Dissecans develop? Was it present at the time of the first operation?

There is nothing in my past development of any diseases which would indicate any late stage of a juvenile affletion. There is also no familial history of bone disease.

It is my opinion that this case could be entirely explained on a traumatic basis. However, the question in my mind as to why this disease entity should appear so often in the young adult is as yet unanswered.

There is no doubt that trauma contributes greatly to the development of Osteochondritis Dissecans. The symptoms, physical examination, $x$-ray, and pathological findings are consistent, and treatment by means of arthrotomy is satisfactory. However; additional studies are necessary to definitely establish the true etfological agent, and the role of trauma as a part of this etfological agent. 
1. Archer and Peterson, Osteochondritis Btsecans, Southern Medical Journal, 23:611-615, 1930.

2. Balensweig I., Osteochondritis of the Knee, Journal of Bone and Joint Surgery, 7:465-468, 1925.

3. Balensweig I., Osteochondritis Dissecans Imvolving the Bntire Arti eulating Surface of the Diatal Bnd, American Journal of Surgery, 39:648-655.

4. Bernstein, MA. Osteochondrit1s Dissecans, Journal of Bone and Joint Surgery, 7:319, 1925.

5. Blanco P1o, Report of a Loose Osteocartilaginous Body in the Knee, 3:104, 1921 .

6. Brackett, R.G. and Hall, C.G., Osteochondritis Dissecans, American Journal of Orthopedic Surgery, $15: 79,1917$.

7. Braileford, J.F., Bone Changes Simulating Tuberculosis and Tumor, Iancet, 1:1487-1492, 1935 .

8. Burghard, Loose Bodies in the Knee, British Medical Journal, 1:247-1892.

9. Christie, A.C., Osteochondritis or Bpiphysitis, Journal of American Medical Association, 87:291, 1926.

10. Colman, B.A., Formation of Loose Bodies in the Knee Joint, Boston Medical and Surgical Journal, CxIIX: 427. 1903 .

11. Calvin, A. R., Clinical Course and Pathology of an Obscure Osteitis Causing Ioose Bodies in the Joints, Ii rinesota Medical Journal, 3:65-70, 1920.

12. Connell, F.G., Loose Bodies in the Knee Jolnt, Annals of Surgery, $43: 247,1906$.

13. Conway, F.M., Intra-articular Osseocartilaginous Loose Bodles, Annals of Surgery, 410-431, 1934. 
14. Conway, F. M., Description of Stages of Condition and Probable Traumatic mtiology, American Journal of Surgery, 38:691-699, 1937.

15. Gurtis, G.M., Osteocartilaginous Loose Bodies in the Knee Joint, Surgery Clinics of North America, $9: 415$, 1929.

16. Delgrade, Ioose Bodies in the Knee, St. Bartholomew Hospital Report, $4: 268,1868$.

17. Bly, I. W., Joint Mice, Annals of Surgery, IXI, 80-82.

18. Fairbanks, H.A.T., Osteochondritis Dissecans, British Journal of surgery, 21:67-82, 1923.

19. Fisher, A.G.T., A study of Loose Bodies Composed of Cartilage or Cartilage and Bone Occurring in Jolnts With Special Reference to The Pathology and tology, 8:493, 1921. Als o found in Lancet, 1921, 839-844.

20. Freiberg, A.H., Osteochondritis Dissecans, Journal of Bone and Joint Surgery, $5: 3,1923$.

21. Freiberg, A.H., Fracture of Second Metatarsal Bone, Surgery, Gynecology and Obstetrics, 19:191.

22. Freiberg and Woolery, P.G., Osteochondritis Dissecans its Nature and Relation to Formation of Joint Mice, American Journal of Orthopedic Surgery, $8: 477,1921$.

23. Funsten, R. V. and Prentice Rinser, Osteochondritis Dissecans as Related to Trauma, Southern Medical Journal, $29: 262-266$, 1936。

24. Galloway and Macey, Osteochondritis Dissecans Causing Bilateral Dislocation of Patellae, Taken from Staff Yeeting of Yayo Clinic, 12:783-784, 1937.

25. Gay, Shedding Cartilage, Pathological Society of Iondon, $6: 398$, 1854 .

26. Ghormley, Jnusual Cases of Osteochondritis Dissecans, Proceeding of Staff Meeting of Hayo Clinic, 7:41-43, 1932 . 
27. Geyman, M.J., Osteochondritis Dissecans, Radiology, $11: 315,1928$.

28. Halstead, A. B., Floating Bodies in Joints, Annals of Surgery, 22:327-342, 1895 .

29. Harris, M.I., Some Internal Injuries of the Knee Jolnt, Transactions of Western Surgical and Gynecological Association, $50: 61,1901$.

30. Henderson, M.S., Osteocartilaginous Bodies in Joints, American Jounnal of orthopedic Surgery, 14:265-230, 1916.

31. Humphrey, G.M., Loose Bodies in the Knee Joints, British Medical Journal, $1: 613,1888$.

32. Hunter, John, Some Observations on the Loose Bodies in Jo1nts, Complete Works of John Hunter, 3:583-588,

33. King, D., Review of 24 Cases, Journal of Bone and Joint Surgery, $14: 535-544$, 1932 .

34. Krida, A., Fracture of Knee Joint, American Journal of Surgery, $9: 558-560,1930$.

35. Iamson, O.F., Moreable Bodies in the Knee Joint, Surgery, Gynecology, and Obstetrics, 33:490-493, 1931.

36. Iane, A., Osteochondritis Dissecans, British Medical Journal, $2: 1207-1208,1893$.

37. Ledrard, Dry Caries of the Knee Joint, Pathological Soclety of Longon, $33: 419$.

38. Iittlejohn, C.W.B., Osteochondritis Dissecans, Australia and New Zealand Journal of Surgery $2: 278-$ $295,1933$.

39. Lockwood, Dxploration of Knee Joint; Removal of Loose Bodies, British Medical Journal, 1:1226-1227, 1889.

40. MacCormac, Loose Cartilages of the Knee Jolnt, Clinical Journal, 209-217, 1896. 
41. MeCannon, J.W., Report of a Case of Osteochondritis Dissecans, Journal of Medicine, 8:80, 1927 .

42. Miller, I.F., Osteochondritis Dissecans of Humerus. Radiology, 27:237-239, 1936.

43. Monteith, W.B.R., Loose Bodies, Lancet, 951-952, 1934.

44. Moulonguet, P., Foreign Bodies in Joints, Journal of Bone and Joint Surgery, 11:353, 1929.

45. Outland, T.A., Osteochondritis and its Relationship to Trauma, American Journal of Surgery, 31:165-166, 1936.

46. Outland and Flood, J.M., Osteochondritis Dissecans of the Acetabulum, American Journal of Surgery, 33: 276-281, 1936.

47. Paget, J., On the Production of some of the Loose Bodies of Joints, St. Bartholomew Hospital Reports, $6: 1,1870$.

48. Paget, J., Loose Bodies in the Knee, Parks International Clinics, 348, 1891.

49. Phemister, D. B., Causes of and Changes in Loose Bodies Arising from Articular Surfaces, Journal of Bone and Joint Surgery, $6: 278-315,1924$.

50. iney and Solly, Loose Bodies in the Blbow Joint, Pathologieal Society of Iondon, 2:248-250.

51. Richards, G. T., Osteochondritis Dissecans, American Journal of Roentgenology, $19: 278-284,1928$.

52. Ridlon, J., Osteochondritis Dissecans of the Patella, Journal of Bone and Joint surgery, 18:230-231, 1936.

53. Stevenson and Henderson, Osteochondrit1s D1ssecans, British Medical Journal, 1:963-965, 1937.

54. Schuman, H.C., Osteochondritis Dissecans, Wisconsin Medical Journal, $27: 214,1928$.

55. Shaw, Osseocartilaginous Body axcised from Knee Joint, Pathological Society of Iondon, 6:82, 1954 . 
56. Hombold, C., Osteochondritis Dissecans of the Patella, Journal of Bone and Joint Surgery, 18,230-231, 1936.

57. Wagoner, G., and Cohn, B.N. E., Resume of Theories of Btiology and Consideration of Heredity as a Factor, Archives of surgery, $23: 1-25,1931$.

58. Wolback and Allison, Osteochondritis Dissecans, Archives of Surgery, 16:1177, 1928.

59. Wychoff, H.J., Osteochondritis Dissecans, Northest Yedicine, 37:105-106, 1938. 